Research Note

\title{
Examining the motivations and future career aspirations of Qatari pharmacy students and alumni: A case study
}

\author{
Banan Mukhalalati ${ }^{\mathrm{a}, *}$, Mayar Ashour ${ }^{\mathrm{b}}$, Asmaa Emad Al Noami ${ }^{\mathrm{b}}$ \\ ${ }^{a}$ Clinical Pharmacy and Practice Department, College of Pharmacy, Health Cluster, Qatar University, PO Box 2713, Doha, Qatar \\ ${ }^{\mathrm{b}}$ College of Pharmacy, Health Cluster, Qatar University, PO Box 2713, Doha, Qatar
}

\section{A R T I C L E I N F O}

\section{Keywords:}

Workforce intelligence

Career aspiration

Pharmacy career

Perceptions

Motivations

Qualitative research

Case study research

\begin{abstract}
A B S T R A C T
Introduction: The Global Pharmacy Workforce report published by the International Pharmaceutical Federation indicated pharmacy workforce shortages and called forstrengthening workforce planning. The low percentage of Qatari students in the College of Pharmacy at Qatar University could negatively impact the fulfilment of the Qatar National Vision and the United Nations' Goals. The aim of this research is to examine the motivations of Qatari pharmacy students and alumni to study pharmacy, and to understand their perceptions of the profession and career aspirations.

Methods: A qualitative case study research was conducted. Data were collected by focus groups and semi-structured interviews, and were analysed thematically.

Results: Research findings suggested that increasing the national workforce was the main motive for students to study pharmacy. The participants' perceptions of the profession varied from pharmacy being a drug sales profession to it being a healthcare profession. Participants' career aspirations included pursuing graduate studies, working in hospitals, and working in academia. The participants were generally satisfied with studying pharmacy, which encouraged them to recommend the major to others. However, the participants were challenged by the lack of societal recognition of pharmacy and by misperceptions about Qatari students, which motivated them to further demonstrate their competencies.

Conclusions: This study will facilitate the understanding of factors that motivate and demotivate Qatari students from joining the pharmacy major and their career aspirations, which will ultimately enhance the development of recruitment strategies geared towards attracting a larger number of qualified and highly motivated Qataris into the pharmacy profession.
\end{abstract}

\section{Introduction}

The World Health Organization (WHO) estimates a global healthcare workforce shortage of 12.9 million by $2035 .^{1}$ This shortage is a major factor for poor health outcomes that could constrain the achievement of universal health coverage by 2030 , which is one of the Sustainable Development Goals (SDGs) launched by the United Nations (UN) in 2015 . $^{2,3-5}$.

The scope of the pharmacy profession has changed from compounding and dispensing medications to include providing patientcentred pharmaceutical care. ${ }^{6}$ Therefore, pharmacists are an integral component of the healthcare workforce and they play an important role in the delivery of healthcare services through their involvement in community, hospital, academic, research, and

\footnotetext{
* Corresponding author.

E-mail address: banan.m@qu.edu.qa (B. Mukhalalati).
} 
policy-making settings. ${ }^{7,8}$

The global reports on the pharmacy workforce and the Global Pharmacy Workforce and Migration Report published by the International Pharmaceutical Federation (FIP) have indicated pharmacist workforce shortages in all sectors. These reports have called for strengthening workforce data systems and pharmacy workforce planning using a needs-based approach in various sectors in order to ultimately improve the global healthcare workforce. ${ }^{1,7,9}$

In 2015, the FIP published the Global Pharmacy Workforce: Intelligence Trends Report, which provided a baseline on the growing global pharmacist capacity building trend. ${ }^{10}$ The report indicated that all WHO regions experienced an increase in the number of pharmacists between 2006 and 2012. Furthermore, the report indicated that the Eastern Mediterranean Region (EMR) has the highest rate of increase in proportional changes in capacity among all WHO regions, based on data from the EMR countries that participated in the surveys. The increase in the proportional change in capacity is mainly due to an increase in the regional education capacity, which is demonstrated by an increase in the number of pharmacy schools since 2000, with the majority of these new schools being privately funded. ${ }^{11,12}$ This surge in the number of pharmacy schools has demonstrated a positive impact on pharmacy practice in these countries, as well as in supplying pharmacists to other countries in the region. ${ }^{7,10,11,13}$ However, the increase in the number of pharmacy schools is not associated with workforce planning and intelligence, which is demonstrated by the dearth of published literature about the pharmacy workforce in EMR. The increase in the number of pharmacy schools without workforce intelligence emphasizes a potential disconnect between the education, regulation, and practice sectors, which negatively impacts the effective and efficient use of the pharmacy workforce within national health systems. ${ }^{7,13,14}$ This disconnect necessitates that pharmacy leaders in different sectors engage in robust pharmacy workforce planning, supported by transformative education practices and significant changes in pharmacy promoting, to meet local health needs. ${ }^{12,15,16,17}$

In that regard, and as an important step, pharmacy schools should aim to recruit students who have profiles that fit the requirements of the school and who are able to undertake the obligation of providing pharmaceutical care aligned with the pharmacist profile desired for the country. ${ }^{18}$ This aim can be achieved by examining students' motivational and demotivational factors as well as career aspirations to choose the pharmacy major. This examination is fundamental in developing admissions practices that reflect regional population characteristics, and in designing recruitment strategies about the pharmacy profession to attract qualified and highly motivated individuals. ${ }^{16,17}$

Several studies have been conducted to explore the motives and career aspirations of students who pursue majors in pharmacy, as well as their preferred areas of practice upon graduation. Regionally, in Kuwait, a failure to be admitted to medicine or dentistry programmes and an interest to cure sick people and become respected healthcare professionals are the main motivating factors for studying pharmacy, with students preferring to work in the public sector upon graduation. ${ }^{18}$ In the United Arab Emirates (UAE), family encouragement, eagerness to obtain a medical professional degree, a desire to work with the healthcare team, and ambition to complete a science-based course are the key motives for students to join the pharmacy school. ${ }^{19}$ At King Saud University in Saudi Arabia the majority of students were not exposed to training programmes in the pharmaceutical industry in order to build their skills in this growing field, which resulted from an inadequate connection between university and pharmaceutical companies. Furthermore, students indicated that the most important factors that influence their career choice are salary and the work environment. ${ }^{20}$ However, in the University of Taif, the influence of family members and the interest of becoming a healthcare professional are the main motives of pharmacy students to study pharmacy, with students reporting uncertainty about the content of the pharmacy programme and their future career options. ${ }^{21}$ In Syria, personal and financial factors are dominant in the career preference decisions of final-year pharmacy students at Damascus University. Hence, working in community pharmacy is the top preferred career setting, with students expressing desires for independent pharmacy ownership. ${ }^{22}$

Internationally, and in the United States of America, anticipatory socialization, career orientation, and a desire to help others influence students' motivations. ${ }^{23}$ In Sierra Leone, school teachers, family, and friends have a great influence on students' decisions to choose a pharmacy major, as does a desire for self-employment in a healthcare-related job, with the majority of students indicating medicine as their first choice of study. ${ }^{24}$ Students in Sierra Leone indicated that drug manufacturing and hospital pharmacy were their most desirable future career options. ${ }^{24}$ Finally, a study conducted in Great Britain revealed that a sizeable proportion of pharmacy students do not intend to practice in the pharmacy profession for which they have trained. ${ }^{25}$

The establishment of the first and only College of Pharmacy (CPH) at Qatar University (QU) in the State of Qatar in 2006 aimed to meet Qatar's growing demand for improved health outcomes. This establishment complies with the third pillar of the Qatar National Vision (QNV) 2030, "human development", which focuses on increasing the Qatari workforce in the health sector, by providing educational programmes with the highest standards to fulfil the labour market's needs. ${ }^{26}$ The CPH offers "an entry to practice" bachelor of science (BSc) degree programme for female students and four post-baccalaureate (graduate) degree programmes for male and female students: doctor of pharmacy (PharmD), master of science (MSc) in pharmaceutical sciences, MSc in clinical pharmacy practice, and doctor of philosophy (PhD) in pharmaceutical sciences. ${ }^{27}$

Since the establishment of the CPH in 2006, 263 students have been admitted to the BSc programme, with Qatari students comprising only $7 \%$ of the total admissions, as illustrated in Fig. 1. The low percentage of Qatari students admitted to the pharmacy programme is consistent with the observed negative attitudes toward science-related majors among Qatari students as they progress from grade 3 through high school. ${ }^{28}$ This low percentage of Qatari students in the pharmacy programme could negatively impact the fulfilment of the QNV (2030) and the National Health Strategy (2018-2022). Therefore, it is important to examine the motivational and demotivational factors, perceptions of the pharmacy profession, and career aspirations of the Qatari students who are currently enrolled in the $\mathrm{CPH}$ and of the Qatari alumni who have graduated from the $\mathrm{CPH}$.

The aim of this research is to examine the motivations of Qatari pre-pharmacy and pharmacy students as well as Qatari alumni to choose pharmacy as their academic major in the $\mathrm{CPH}$ at QU, to understand their perceptions of the pharmacy profession, and to 

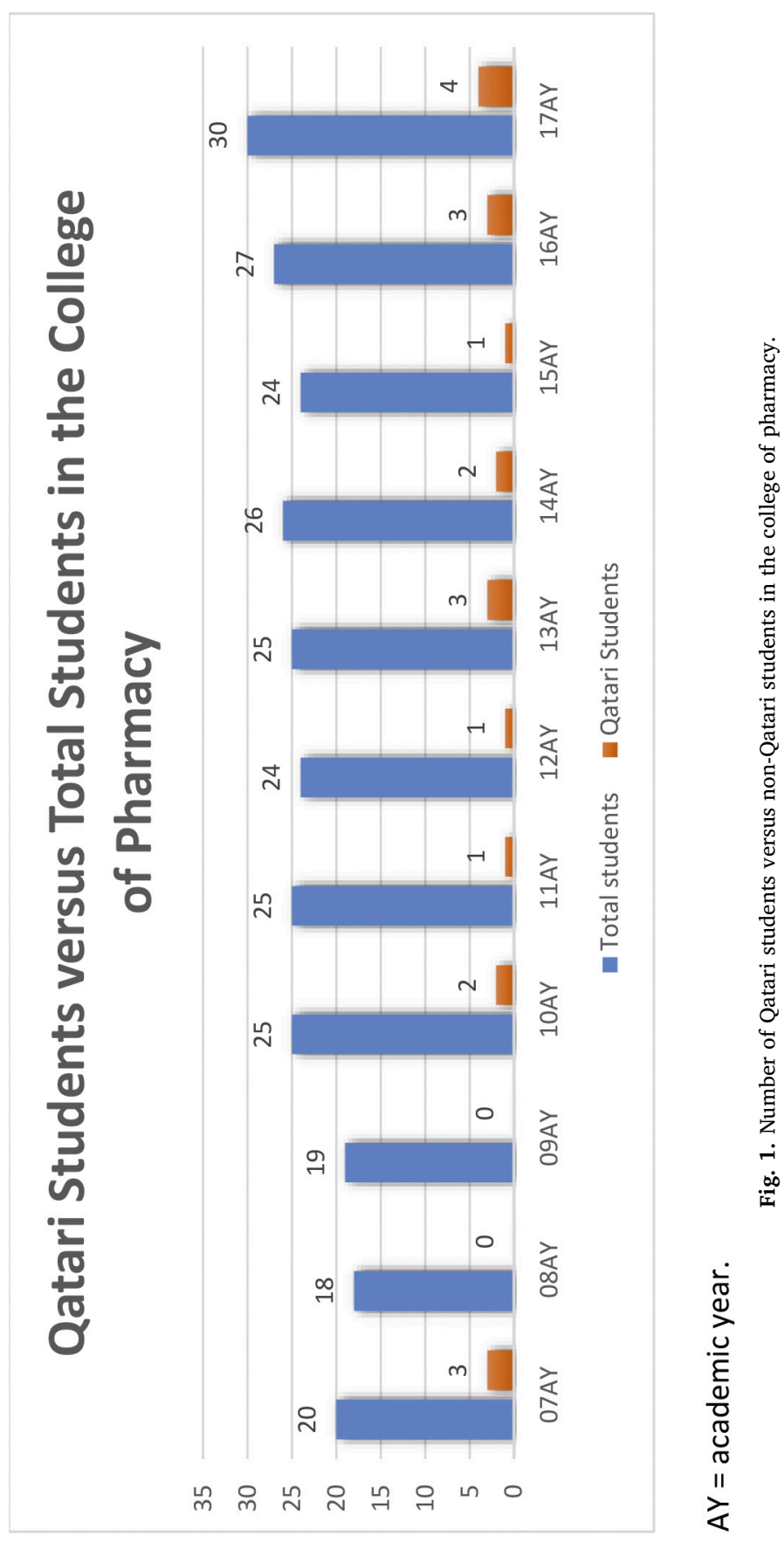
identify their career aspirations. This examination will enhance the understanding of factors that motivate or deter high school and pre-pharmacy students from joining the $\mathrm{CPH}$ at QU. Furthermore, this examination will facilitate the development of awareness campaigns about the pharmacy profession and the improvement in recruitment strategies designed towards attracting a larger number of qualified and motivated Qatari students into the pharmacy major. Finally, this examination will enrich the understanding of the national supply and demand and in establishing a critical mass of competent Qatari pharmacy workforce, who will continue to practise in Qatar. This will ultimately contribute to achieving QNV and the UN's SDGs globally.

The specific objectives of this research are: (1) Investigate the motivational factors leading Qatari pre-pharmacy and pharmacy students and alumni to choose pharmacy as an academic major, by answering the research question, why do Qatari pharmacy students choose to study pharmacy?, (2) Examine the perceptions of Qatari pre-pharmacy and pharmacy students and alumni regarding the pharmacy profession and the pharmacist role in Qatar, by answering the research question, how do Qatari pharmacy students perceive the pharmacy profession?, and (3) Explore the future career aspirations of Qatari pre-pharmacy and pharmacy students and alumni, by answering the research question, how do Qatari pharmacy students perceive their career options?

\section{Methods}

\section{Design and theoretical approach}

Considering the importance of recruiting Qatari students to pursue pharmacy majors, a single descriptive case study approach was used to gain a detailed understanding of the motivational factors leading Qatari students and alumni to study pharmacy and their career aspirations. ${ }^{29}$ A case study approach was selected because it provides an in-depth examination and understanding of a real-life phenomenon that researchers cannot change over time. ${ }^{30}$ Furthermore, the case study approach was selected to achieve methodological congruence between the research questions and methods because such an approach answers the "how" and "why" research questions, that are explanatory and descriptive rather than exploratory. ${ }^{31,32}$

Social constructivism was selected as the interpretative framework because it focuses on examining the complex, social, and subjective meanings of the world, ${ }^{29}$ while recognizing the influence of researchers on the research. Social constructivism comprises specific philosophical assumptions about reality (ontology), knowledge (epistemology), values (axiology), and an approach to inquiry (methodology). ${ }^{32}$ For the ontology, social constructivists argue that there are multiple subjective realities constructed through social experiences, and thus perceptions are different for each participant. For the epistemology, social constructivists state that knowledge is socially constructed between the researchers and researched. Each participant in this study has developed individual meanings related to the researched topic; therefore, the researchers refer to participant quotes in the findings. For the axiology, social constructivists explain that researchers' values influence researchers' interpretation of the data. ${ }^{30}$ Therefore, the researchers acknowledge the influence of participants' diverse values and reflect on their own values in the discussion. Finally, for the methodology, social constructivists argue that researchers use inductive and deductive reasoning to examine a topic within its context before making theoretical generalizations. Therefore, the researchers use inductive and deductive methods by asking the participants openended questions.

\section{Study site and duration}

The research was conducted at the QU CPH. The timeframe of the study was February to December 2018.

\section{Participant recruitment}

Purposeful sampling was used to ensure that all Qatari pharmacy students and alumni were recruited. ${ }^{29}$ The sample included Qatari pre-pharmacy students (PR), Qatari pharmacy students in different professional years (professional year 1 [P1], professional year 2 [P2], professional year 3 [P3], and professional year 4 [P4]) and Qatari alumni (A). Based on the data obtained from the CPH registration office, a total of 29 Qatari students were admitted to the CPH between the 2007 and 2017 academic years. Due to the small number of admitted Qatari students, all Qatari students and alumni with updated contact information were invited to participate. Of the 29 students and alumni, 27 were invited by email to participate in the research. Of the 27 invited students and alumni, 16 agreed to participate (one PR, 10 pharmacy students, and five A), as indicated in Table 1. The invited participants were sent an

Table 1

Participant recruitment.

\begin{tabular}{|c|c|c|c|}
\hline Population & Total number & Invited & Accepted \\
\hline Pharmacy student & 12 & 12 & 10 \\
\hline Pre-pharmacy students & 7 & 7 & 1 \\
\hline \multirow[t]{4}{*}{ Alumni } & PharmD students & 2 & 2 \\
\hline & Master students & 1 & 0 \\
\hline & Practicing pharmacist with PharmD degree & 6 & 3 \\
\hline & Practicing pharmacist with Master degree & 1 & 0 \\
\hline
\end{tabular}

PharmD $=$ doctor of pharmacy. 
email with the participant information leaflet and consent forms. In the participant information leaflet , all relevant information on the objectives, rights, risks, and general information related to the study was provided. Upon agreeing to participate, the participants signed the consent forms, which were then collected by the researcher.

\section{Data collection}

One focus group (FG) and six semi-structured interviews were conducted to collect data in this study. The FG was conducted with 10 Qatari pharmacy students (P1, P2, and P3) who had similar backgrounds and experiences and were available to participate at the same time. Five semi-structured interviews were conducted with the five Qatari alumni due to difficulties in finding a common time suitable for their different work schedules. Additionally, a semi-structured interview was conducted with the Qatari prepharmacy student who consented to participate in the study. Topic guides were designed with questions formulated to explore three research objectives: motives to study pharmacy, perceptions of the pharmacy profession, and career aspirations. These research objectives guided the deductive thematic data analysis. All FGs and interviews were audio recorded to allow the researcher to focus on the discussion and to ensure the accurate collection of details during the sessions. The recordings were then transcribed verbatim. ${ }^{33,34}$ All information in the transcripts was anonymized by using alphanumerical codes, with "PR" assigned to pre-pharmacy students, "P" to pharmacy students, and "A" to alumni. Subsequently, transcripts were double checked by each researcher, and stored on a password protected laptop to ensure the confidentiality of data. Transcripts were sent to participants to review their responses to ensure that they reflected their views. ${ }^{35}$

\section{Data analysis}

Thematic analysis was used for data analysis, relying on deductive and inductive coding and utilizing computer-assisted coding software (NVIVO $12^{\mathrm{O}}$ ). ${ }^{36,37}$ Deductively, items (questions) in the topic guides were used to organize the analytical priorities for analysing data from participants. Inductively, other ideas and views that emerged during the discussion, that were not part of the topic guides but were indirectly related to the research questions, were also analysed. ${ }^{31}$ Thematic analysis was performed by two researchers independently in the following stages: familiarization with the data by re-reading transcripts, identification of significant phrases that are related to the research questions, formulation of the meanings of the phrases and clustering of the themes common to all of the transcripts, and integration of the themes into an in-depth comprehensive description of the phenomenon. ${ }^{29}$ The research team met regularly throughout the data analysis process to reduce the possibility of researcher bias. Any discrepancies were resolved by discussion and, if agreement was not reached, by consensus.

Ethical approval

Prior to the research being conducted, the research was approved by the Qatar University Institutional Review Board, number: QU-IRB 893-E/18.

\section{Validation and quality}

Validation and quality in qualitative research use qualitative terms to distinguish them from quantitative research validation. ${ }^{29}$ The rigour of this study is based on Lincoln and Guba's ${ }^{35}$ trustworthiness criteria, which are based on a naturalistic research perspective, including credibility, conformability, transferability, and dependability. ${ }^{31}$ Measures used to fulfil various quality criteria are indicated in Table 2 .

Table 2

Measures to attempt quality criteria.

\begin{tabular}{|c|c|c|c|}
\hline Quality criterion & Measures & & \\
\hline Confirmability & $\begin{array}{l}\text { Audit trail:audio recordings, } \\
\text { transcripts, and coding are } \\
\text { available }\end{array}$ & $\begin{array}{l}\text { Research methods description:comprehensive } \\
\text { description of research methods }\end{array}$ & $\begin{array}{l}\text { Data triangulation:multiple sources of data } \\
\text { and various participants categories were } \\
\text { utilized }\end{array}$ \\
\hline Dependability & $\begin{array}{l}\text { Peer review:oversight and audit of } \\
\text { the research process by peer } \\
\text { researchers }\end{array}$ & $\begin{array}{l}\text { Inter-coder reliability testing:the researchers } \\
\text { coded the data independently and compared their } \\
\text { results to reach agreement }\end{array}$ & $\begin{array}{l}\text { Intra-coder reliability testing:data were } \\
\text { coded, left for two weeks, and then recoded } \\
\text { to compare the results }\end{array}$ \\
\hline Credibility & $\begin{array}{l}\text { Reflection recording: a research } \\
\text { diary was maintained to reflect on } \\
\text { the researchers' influence and } \\
\text { biases }\end{array}$ & $\begin{array}{l}\text { Proper data analysis strategies: interpretation of } \\
\text { the data was ensured to be correct by following } \\
\text { the proper data analysis strategies }\end{array}$ & $\begin{array}{l}\text { Member/participant checking:transcripts } \\
\text { and findings were sent to participants to } \\
\text { confirm that they reflected their } \\
\text { perspectives }\end{array}$ \\
\hline Transferability & $\begin{array}{l}\text { Data interpretation and } \\
\text { discussion: a clear description was } \\
\text { made of how data were analysed } \\
\text { and interpreted }\end{array}$ & $\begin{array}{l}\text { Recording research details: details about the case } \\
\text { study were provided by describing the case's } \\
\text { setting, context, and the research methods }\end{array}$ & $\begin{array}{l}\text { Research write up: information related to } \\
\text { this case study was written up }\end{array}$ \\
\hline $\begin{array}{l}\text { in the form of a } \\
\text { manuscript and a } \\
\text { poster }\end{array}$ & & & \\
\hline
\end{tabular}


Table 3

Deductive and inductive themes.

$\begin{array}{ll}\text { Data analysis approach } & \text { Themes } \\ \text { Deductive themes (D-T) } & \text { Motivations to study pharmacy (D-T1) }\end{array}$

Perceptions of pharmacy profession (D-T2)

Career aspirations and future plans (D-T3)

Inductive (I-T)
Subthemes

Qatari national workforce shortage (D-T1.1)

Encouragement from family and/or friends (D-T1.2) Interest in the medical field (D-T1.3)

$\mathrm{CPH}=$ College of Pharmacy.

\section{Results}

Thematic analysis revealed three main overarching themes in the data. ree Three themes primarily comprised the subthemes developed deductively from questions in the topic guide, as described in the Methods section. Two other themes were derived from inductive analysis of the data. Deductive and inductive themes and their subcategories are presented in Table 3.

\section{Deductive themes}

Motivations to study pharmacy:Understanding pharmacy students' motives to study pharmacy is key in workforce planning. Three main factors influenced participants' decisions to study pharmacy: the Qatari national workforce shortage, encouragement from family and/or friends, and interest in the medical field.

Qatari national workforce shortage: The need to have more Qatari pharmacists in the profession was identified as the main motive for studying pharmacy among pharmacy students and alumni. For example, during the FG, a pharmacy student stated that she often sees non-Qatari pharmacists, but not Qatari pharmacists, at the practice sites:“...whenever you go to hospitals, you always come across non-Qatari pharmacists. So, you don't see your own people in your own country in the stage of its development. This kind of motivates you to be a part of the profession, when you don't have a lot of Qataris in practice...." PS2 In the same context, one alumnus indicated that the pharmacy career is truly lacking a Qatari workforce; hence, there is an urgent need to have more Qatari pharmacists in this field.

Encouragement by family and/or friends: Encouragement by a family member or a friend was the next predominant motive for the majority of participants. For example, a pharmacy student was encouraged by her sister, who studied pharmacy, to join the pharmacy college. Another pharmacy student indicated that her brother, who is a psychologist, encouraged her to study pharmacy: “... my older brother motivated me; he is a psychologist, so he encouraged me by saying: go and study pharmacy, you will be a good pharmacist in the future, you will help your country as a Qatari. There are a lot of non-Qatari pharmacists. Go ahead!...” PS6 An alumnus indicated during the interview that her mother, who works in the pharmacy career, motivated her to choose pharmacy, while another alumnus indicated that her best friend, who is a clinical pharmacist and holds a PharmD degree, encouraged her to study pharmacy: “... My high school clinician and my best friend, who is a pharmacist with a PharmD, she kind of directed me towards this path..." A1

Interest in the medical field: Interest in working in the medical field appeared to be one of the motives of pharmacy students to join the pharmacy college. For example, a pharmacy student expressed her interest in working in the medical field, but not as a physician: “..... When I graduated from high school, I decided to choose a medical major, but other than medicine....” PS6

In an interview conducted with the prepharmacy student, an interest in studying chemistry and human biology was the main motivation to choose pharmacy, followed by an interest in exploring the pharmacy major and encouraging other Qatari students to study pharmacy: “...I am generally a good student in chemistry and human biology, so I am interested in studying in a major that focuses on them. In Qatar, there are few Qatari pharmacists and few Qatari pharmacy students. I want to experience pharmacy and see why Qatari students don't choose pharmacy and then to encourage students from my nationality to study pharmacy...." PR1

The data suggest that the Qatari national workforce shortage in the pharmacy profession is the main motive for studying pharmacy, followed by encouragement by family and/or friends and interest in the medical field.

Perceptions of the pharmacy profession: The second theme focused on changes in students' perceptions of the pharmacy profession before and after they joined the college and became aware of the role of pharmacists. The participants predominantly indicated that before joining the $\mathrm{CPH}$ one of the main demotivating factors was their previous perception of the pharmacy profession as a drug selling profession. For example, a pharmacy alumnus indicated that she had never heard about the clinical pharmacist role before joining the college: “...Before getting in, I never heard of clinical pharmacy. My only thought was that when you graduate from the College of Pharmacy, you will work in a community pharmacy doing nothing other than selling medications..." A2

Another alumnus, on the other hand, recognized the significant role that pharmacists play on healthcare teams even before joining the college, which influenced her interest in being a pharmacist: “...I heard about clinical pharmacy prior to entering to the college, so I was aware from beginning about what clinical pharmacist means and its important role on the healthcare professional team..." A3

In the interview conducted with the prepharmacy student, she explained that she previously had a very limited perception of the pharmacy profession, which initially negatively impacted her motivation to join the CPH: “...Before, I had an unclear perception about the pharmacy profession, like they just dispense and sell medications for people. This is so limited...." PR1

The perceptions of the participants changed after they joined the $\mathrm{CPH}$, particularly after they went through experiential rotations in various practice settings as part of their pharmacy education. For example, a pharmacy student mentioned that there are other 
important roles of pharmacists in addition to being a pharmacist in a community pharmacy. Another pharmacy student indicated that after joining the $\mathrm{CPH}$, she realized that pharmacists are drug experts who can contribute to the final decision of the healthcare team about the most suitable medication to be prescribed to a patient. Furthermore, in the interview conducted with the prepharmacy student, she explained that the pharmacist's role is key in the healthcare system: “...I think pharmacists are very important in the healthcare system. Without their role, something important will be missing..." PR1

The perceptions of almost all alumni of the pharmacy profession changed positively after they started working or after they joined the post-graduate PharmD programme. For example, an alumnus emphasized the role of pharmacists in patient-centred care by influencing the individual therapy plan. Another alumnus mentioned: “...The pharmacist has a great role in the medical team like when they are in the round, the consultants are asking the pharmacist what do you think about this regimen? do you agree about this medication" do you have any opinion", so like the pharmacist has big impact on the final therapeutic decision..." A4

These findings suggest that Ppharmacy students and alumni previously perceived the pharmacist role to be drug sellers. However, this perception has changed after joining the $\mathrm{CPH}$ to considering pharmacists as important members of healthcare teams.

Future plans and career aspirations: This theme describes student and alumni future plans and career aspirations. The participants explained that the pharmacy profession is a progressive profession with the advantage of providing various career opportunities, including in the areas of hospital pharmacy, community pharmacy, academia, research, and private pharmacy business. Some pharmacy students mentioned their career aspirations in the pharmacy profession in Qatar, stating that the pharmacy profession is a changing and developing profession, and consequently, many opportunities are opening up. For example, a pharmacy student mentioned: “...It's not just about working in a community pharmacy. We have several career options that we can work in.... PS5"

Pharmacy students predominantly indicated their interest in working as hospital pharmacists immediately after graduation to gain professional experience. For example, a pharmacy student said: “...I like to work in the hospital and to collaborate with other healthcare professionals..." PS7 Another pharmacy student indicated her interest in working in the hospital setting as a clinical pharmacist after she finished her post-graduate PharmD degree, while few students indicated their interest in joining a post-graduate programme, such as Masters or PhD programmes in pharmacy, so that they could pursue an academic career. “...Many people told me that many people don't like hospitals because you will see sick people; therefore, academia is good..." PS5

One student, however, expressed her interest in establishing a pharmacy business and opening her own community pharmacy: “... Maybe I will have my own pharmacy, because my sister studied business, so maybe she can use her business skills, and I can use my pharmacy knowledge to make this happen...". PS6 The prepharmacy student, on the other hand, indicated her willingness to practise immediately after graduation from the BSc programme before pursuing graduate study: “...Before I complete any further studies, I think that I should first practise and work in a hospital to gain practical experience and enhance my [curriculum vitae] CV. Then, maybe I will study for a PharmD..."PR1

Alumni indicated different future plans and career aspirations. For example, several alumni indicated their willingness to take the board exam, followed by joining a residency programme: “...Actually, two plans, to take a board exam, this is the first plan. The second plan is to be qualified to apply to the residency programme...” A3 Other alumni expressed an interest in specializing and working in medication safety and quality. For example, an alumnus said: “...I am not thinking in the near future to change my job as a hospital pharmacist. However, in the long-term future, I am going to join and work in the medication safety and quality department. It is much better; I feel that working in the quality department could be like an administration and organization type of work..." A5 One alumnus expressed her interest in joining academia so that she would have teaching and research responsibilities and duties: "...A pharmacist can do a lot of thing not only related to medications. A pharmacist can join an academic career and work as a lecturer or a researcher, which is more what I am looking for... " A4.

Surprisingly, one alumnus conveyed interest in pursuing graduate studies in a major other than pharmacy, such as finance or management, while working in a hospital as a clinical pharmacist: “...My plan is to do a Masters in something away from pharmacy. To be honest, like something in finance and management, so that I'll have two different backgrounds and experiences in pharmacy and in business..." A2

The data above indicate that Qatari students and alumni recognised the various job options and future opportunities offered by a career in pharmacy.

\section{Inductive themes}

Students' experiences with studying at the college of pharmacy: The students' experiences inductive theme focuses on two subthemes. The first concerns the level of satisfaction of the Qatari pharmacy students with their studies at the $\mathrm{CPH}$, and the second concerns the challenges that students faced in studying at the $\mathrm{CPH}$.

Level of satisfaction of the Qatari pharmacy students with their studies at the CPH: Predominantly, students indicated their satisfaction with studying in a college of pharmacy that has a Canadian accreditation by the Canadian Council for Accreditation of Pharmacy Programmes (CCAPP), which demonstrates the high standard and quality of the curriculum. Graduating from a highquality programme opens doors for future career opportunities, as indicated in the following student's quote: “...The pharmacy college at QU has a strong curriculum, and this will allow me to continue my graduate studies, such as for a PhD, in a very well-known university, for example, Harvard University..." PS4 Another student emphasized the great effort of the CPH to attract Qatari students and to help them succeed and thrive in the college.

However, one student indicated that she was dissatisfied with studying at the CPH immediately after she joined the pharmacy programme. Over time, she gradually started to enjoy the pharmacy major: “... When I was admitted to the CPH, I was happy but not satisfied. However, now, I am liking it more. Now, every time when we study something, I feel that I want to know more about it. Now, I feel 
that I want to become a pharmacist, and I want to graduate quickly!..." PS5

Satisfaction with studying at the CPH was even more evident among alumni because they had started applying the knowledge and skills developed in the $\mathrm{CPH}$ in their practical experience. For example, one alumnus mentioned her satisfaction with the problemsolving, critical analysis, and communication skills that she had developed by studying in the $\mathrm{CPH}$. Another alumnus stressed the role of the college in teaching her to use evidence-based knowledge in her decisions: “... When we are in clinical rounds with members of the healthcare team, everyone says that the students from Qatar University are different. They are goal oriented, and they use evidence-based knowledge, which is something unique. It is a great advantage that our college taught us about how to support our recommendations with evidence and primary literature..." A4

Several alumni indicated their satisfaction with the international rotations and research opportunities that they had during their undergraduate studies, which supported students' development as life-long learners and researchers. For example, one of the alumni mentioned: “...the college always motivated and sponsored us to do research, to attend conferences, and to have international internships or rotations. All of these are factors had impact on student, because they represented great opportunity not found in any colleges. All of these factors pushed us to give our best to our career later..." A2

When the participants were asked whether they would recommend studying pharmacy at the CPH to others, pharmacy students and alumni indicated their willingness to advocate for the $\mathrm{CPH}$ and the pharmacy profession, as suggested in the following quote:“... Yes, I will recommend it for sure, because the pharmacy is a really good, promising profession..." A4 However, an alumnus clarified that she would recommend the pharmacy major, despite her dissatisfaction with a few aspects of the CPH: “...I can just recommend it because we need Qatari pharmacists in this profession. Maybe my dissatisfaction is my own problem with certain issues, which might not be problematic for others..." A5

Challenges associated with studying at the $\mathbf{C P H}$ : Almost all pharmacy students indicated that the main challenge that they faced during their studies was people's general perception that Qatari students are not competent enough to study pharmacy. For example, one of the students indicated that people in the college used to tell them that Qatari students would not be able to survive in the competitive, stressful, and challenging environment of the $\mathrm{CPH}$. “...There are people in this college that make us feel that as Qatari students, we can't survive in this college. Even some professors they think that as Qataris, we don't study well, and we don't work hard. This is totally wrong. We spend most of our time studying only, without getting time for our families..." PS1O

A few alumni indicated that one of the challenges that they faced was that the PharmD programme provided them with basic knowledge and skills that were not adequate in their clinical practice: “...I wanted more. The CPH graduated me from a PharmD programme with only basic knowledge and skills. So, my satisfaction with this point is not great..." A3

A few other alumni indicated that the lack of appreciation of the pharmacy career and the limited career options that they had upon graduation was one of the major challenges:“...The pharmacy profession is not appreciated by other people. Additionally, we have limited options for working in Qatar. We do not have that many options that you can move between jobs in hospitals. I mean, only either Hamad Medical Corporation (HMC) or Sidra Hospital. Nationals cannot go and work in private hospitals, like Al-Ahli, which limits our opportunities..." A5

Another alumnus also emphasized the limited opportunities: “...You don't have that many options available other than being a clinical pharmacist or specialist. There are always limits, so if you want to do something else, or you want to achieve another goal, then it is very important that you do post-graduate studies in something other than pharmacy. Maybe like a Master degree in business, but in pharmacy it's always limited, not like engineering or other majors..." A2

Based on the data above, pharmacy students and alumni were generally satisfied with studying the pharmacy major at the $\mathrm{CPH}$ and would recommend this major to others. However, students and alumni had a few challenges related to lack of societal recognition of pharmacy as a profession and limited career options, as well as the misperception of Qatari students as weak students by some faculty in the college.

\section{Discussion}

To our knowledge, this is the first study conducted in Qatar to examine the motivations of Qatari pharmacy students and alumni to study pharmacy and to understand their perceptions of the profession and their career preferences.

Motives to study pharmacy

The data from this study indicated that increasing the national workforce in the pharmacy profession was the main motive for Qatari students to study pharmacy. This motive can be attributed to the recognition of participants of the shortage of practising Qatari pharmacists in the country, as the majority of practising pharmacists in Qatar are expatriates who received their bachelor degrees in Egypt, India, and Jordan. ${ }^{11}$ Similarly, 93\% of pharmacy students in the CPH at QU are non-nationals who can be expected to leave the country at any time in their careers. Literature about the nursing profession in Qatar indicated that Qatar relies heavily on an expatriate healthcare workforce, with only five to 10 percent of the workforce being Qatari. Studies suggest that the low percentage of Qatari workforce in healthcare professions reflect the limited attractiveness and awareness of healthcare as a profession among the Qatari population, which have made workforce planning a crucial component of future healthcare strategy. ${ }^{38}$ The shortage in the national workforce in Qatar is consistent with that in the UAE, which is expected to be more drastic by $2020{ }^{19}$ because the majority of pharmacy students are non-nationals who are also expected to leave the country at some point after graduation. It is important, therefore, to attract Qatari students to pursue the pharmacy major after examining their motives to tailor community outreach campaigns based on these motives. 
Furthermore, the research findings emphasized that encouragement from family members to study pharmacy and interest in getting a health profession degree were key motives for selecting the pharmacy major. These findings align with those of previous research conducted in Saudi Arabia, Kuwait, the UAE, Australia, and Sierra Leon about students' motives for choosing pharmacy as a major. ${ }^{18,19,24,39}$

\section{Perceptions about the pharmacy profession}

This research highlighted the dominant perception about the pharmacy profession among participants, which varied from pharmacy being a drug sales profession to it being a health and patient care profession. The perception about the pharmacy profession being a drug selling profession could demotivate potential Qatari from joining the $\mathrm{CPH}$, and thus understanding factors that motivate and demotivate students from joining the pharmacy profession is fundamental.

The variation in perception of pharmacy profession among participants could be related to the academic year of students participating in the research and to their levels of exposure to real professional practice through practical placement or practice as pharmacists or clinical pharmacists. When students and alumni are more involved in the clinical practice, their perceptions about the pharmacy career develop. This finding suggests that awareness campaigns and recruitment events should ideally involve Qatari students and alumni who experienced the significant role of pharmacists in providing patient care, and who can be the best advocate of the pharmacy profession. $\mathrm{CPH}$ can learn from the University of Calgary in Qatar experience where nursing students have become self-advocates and role models, ${ }^{40}$ who were involved in privileged communication with potential students, patients, and families in different venues and platforms. ${ }^{41}$

Students perception about the pharmacy profession being a drug sales profession can be attributed to the role of the majority of pharmacists working in community pharmacies, who practise only the dispensing role, without providing patient-centred pharmaceutical care. ${ }^{42}$ These findings suggest that the scope of practice of pharmacists in Qatar should be expanded in governmental, public, private, and community sectors, adapting to and adopting the scope of practice of other countries with more developed pharmacist roles. ${ }^{1,7}$ This suggestion is consistent with that of a study in Kuwait to the Ministry of Health to expand pharmacists' scope of practice, both at the community and hospital levels, for pharmacy graduates to understand the professional practice. ${ }^{18}$

In Qatar, the nursing career struggled with a negative stereotyped image of the profession, which created serious challenges for recruitment and retention of Qatari students. ${ }^{40}$ The nursing profession was viewed as a dishonorable job that could risk female marriage, due to the presence of male patients and colleagues and the extensive workload, ${ }^{43,44}$ However, the image of the nursing profession was elevated through governmental support and mass media campaigns. These mass media awareness campaigns involved Qatari students and graduates who demonstrated that nurses are caring professionals and respectful of the cultural values of the population of Qatar, ${ }^{40,43}$ which resulted in an increase of Qatari student recruitment. ${ }^{41}$ With that in mind, future recruitment strategies about the pharmacy major could focus on modifying students' misconceptions and on enhancing the societal image of the pharmacy profession by emphasizing the significant role of national pharmacists. This suggestion is consistent with the observed needs in Saudi Arabia to organize awareness programmes for high school students about the pharmacy profession. ${ }^{21}$

\section{Career aspirations and future plans}

Another major finding of this study concerns the career aspirations and future plans of Qatari students and alumni. Various job options and future opportunities are available for graduates from the $\mathrm{CPH}$, which includes pursuing graduate studies in pharmacy or other majors, working in academia and research, working in hospital or clinical pharmacies, or working as medication safety and quality specialists. The availability of various career options is important in placing graduates appropriately based on their interests and aspirations. The findings on student and alumni interest in working in a hospital setting are consistent with those of other research conducted in the region. For example, almost 50\% of students in Kuwait, and the majority of students in the UAE and Saudi Arabia expressed their interest in working in hospital pharmacies. ${ }^{18,19,20}$ However, in New Zealand, the majority of students stated that they would like to own a community pharmacy. ${ }^{45}$ In the United Kingdom (UK), The majority of students indicated that previous work experience, salaries, and the Clinical Pharmacy Practice course were influencing factors in their career choices. ${ }^{46}$ These findings indicate that the availability of various career options is important in placing graduates appropriately based on their interests and aspirations. Furthermore, the findings highlight the significance of introducing students to various career opportunities during their undergraduate studies through practical placements and career fairs.

\section{Satisfaction with studying pharmacy at the $C P H$}

Pharmacy students and alumni confirmed their general satisfaction with studying the pharmacy major at the CPH. This satisfaction is explained by the high standards of teaching and learning in the college, which is demonstrated by the CCAPP accreditation, and by the research and international engagement students receive during their studies. Therefore, participants indicated that they would recommend this major to others, even if there were some areas for improvement in the $\mathrm{CPH}$, because of the critical need to have Qatari pharmacists in the profession. These findings are similar to the findings of the UAE, UK, and Australian studies in which the majority of students were satisfied with the choice of pharmacy as a major because they felt that pharmacy is a good profession, especially after being exposed to practical placements. ${ }^{19,39}$ However, in Australia, students indicated the need for more placements and for career support. ${ }^{39}$ Similarly, in Saudi Arabia, only half of the students reported their satisfaction with the pharmacy programme, because they were not oriented to the content and challenges of the pharmacy programme and to their future 
career options. ${ }^{21}$ Finally, in Kuwait, two-thirds of students indicated that the pharmacy programme developed their problem-solving and communication skills, but that there were challenges with excessive workload. ${ }^{18}$

\section{Challenges associated with studying pharmacy at the $\mathrm{CPH}$}

The last theme in this research indicated that Qatari pharmacy students and alumni were challenged with misperceptions of Qatari students as weak students by some faculty in the college. This misconception can be explained by the admission process; given that the number of non-Qataris who apply to the college is much higher than that of Qataris, the average high school score for newly admitted non-Qataris is usually higher, while both categories satisfy the admission requirement of the college. This misconception was a motivation for Qatari students to demonstrate their abilities and competencies to continue in this professional field, which certainly added to their stress. Furthermore, Qatari pharmacy students and alumni were challenged by a lack of societal recognition of pharmacy as a profession, which can be explained by the lack of a standardized scope of practice across all practice settings. These findings are consistent with those of a previous study conducted in Australia, where more than a third of students expressed concern over job opportunities, decreasing wages, and limited recognition of the amount of work involved in being a pharmacist. ${ }^{39}$

\section{Limitations and future research}

The usefulness of this research is limited by several factors. The study focused on Qatari students and alumni to meet the aim of the research, which may not necessarily correlate with other students and alumni, because Qatari students and alumni represent a small percentage of the total number of students and alumni. Furthermore, this study used only qualitative data collection methods, including FGs and interviews, which might have prevented some students from fully expressing their real opinions. Finally, the categorization of respondents as "students" or "alumni" resulted in failure to recognize the diversity within each group. These limitations can be addressed by conducting future research that focuses on understanding the motives and career aspirations of all students and alumni in Qatar, not only Qatari, including male students hereafter the CPH commences male admission. This understanding can be enhanced by conducting qualitative and quantitative research, while focusing on the variety of perceptions among students from different academic years and among alumni with various career paths. Furthermore, future research should examine the existing national workforce intelligence efforts to identify gaps in these efforts and build on them while learning and benchmarking with other successful national and global workforce intelligence models.

\section{Conclusions}

This research emphasizes challenges and obstacles to the national supply of Qatari pharmacists, which is a preliminary step in national pharmacy workforce planning. Furthermore, the results of this research highlight potential areas for improvement in QU CPH's recruitment strategies and provide a guide for future awareness campaigns, so that they meet Qatari students' interest, address their potential misconceptions, and educate them about the significant role of pharmacists in patient care.

\section{Acknowledgments}

The authors would like to acknowledge the funding agency: Qatar University Internal grant: QUST- ST CPH 20

\section{References}

1. Bates I, John C, Bruno A, Fu P, Aliabadi S. An analysis of the global pharmacy workforce capacity. Hum Resour Health. 2016;14(1):61. https://doi.org/10.1186/ s12960-016-0158-z.

2. Hongoro C, McPake B. How to bridge the gap in human resources for health. Lancet. 2004;364(9443):1451-1456. https://doi.org/10.1016/S0140-6736(04) $17229-2$.

3. World Health Organization. Tracking universal health coverage: 2017 Global monitoring report. December 2017. Accessed 14 June 2020. https://www.who.int/ healthinfo/universal_health_coverage/report/2017/en/.

4. World Health Organization. Tracking universal health coverage: first global monitoring report. 2015. Accessed 14 June 2020. https://www.who.int/health_ financing/documents/tracking-uhc/en/.

5. World Health Organization. The International bank for reconstruction and development, the world bank. Tracking universal health coverage. Global monitoring report: Executive summary. 2017. Accessed 14 June 2020. https://apps.who.int/iris/bitstream/handle/10665/260522/WHOHIS-HGF-17.2-eng.pdf;jsessionid= 6C116E495A922BCBAED971692F8DBDBA? sequence $=1$.

6. AlbaneseRouseSchlaifer NPMJM. Council on Credentialing in Pharmacy. Scope of contemporary pharmacy practice: roles, responsibilities, and functions of pharmacists and pharmacy technicians. J Am Pharm Assoc. 2004;50(2):e35-e69. https://doi.org/10.1331/JAPhA.2010.10510.

7. Bader L, Bates I, John C. From workforce intelligence to workforce development: advancing the Eastern Mediterranean pharmaceutical workforce for better health outcomes. East Mediterr Health J. 2018;24(9):899-904. https://doi.org/10.26719/2018.24.9.899.

8. Smith MA. Pharmacists and the primary care workforce. Ann Pharmacother. 2012;46(11):1568-1571.

9. Chan XH, Wulijii T. Global pharmacy workforce and migration report: a call for action. International Pharmaceutical Federation. 2006 . Accessed 14 June 2020. https://www.fip.org/file/1422.

10. John C, Bates I. Global pharmacy workforce intelligence: trends report 2015. International Pharmaceutical Federation. 2015. Accessed 14 June 2020. https:// www.fip.org/file/1401.

11. Kheir N, Zaidan M, Younes H, El Hajj M, Wilbur K, Jewesson PJ. Pharmacy education and practice in 13 Middle Eastern countries. Am J Pharm Educ. 2008;72(6):133. https://doi.org/10.5688/aj7206133.

12. Alhamoudi A, Alnattah A. Pharmacy education in Saudi Arabia: the past, the present, and the future. Curr Pharm Teach Learn. 2018;10(1):54-60. https://doi.org/ 10.1016/j.cptl.2017.09.014. 
13. Bajis D, Moles R, Hosp J, Chaar B. Stakeholders' perspectives on quality assurance in the Eastern Mediterranean region. Am J Pharm Educ. 2018;82(10):6482. https://doi.org/10.5688/ajpe6482.

14. Bader LR, McGrath S, Rouse MJ, Anderson C. A conceptual framework toward identifying and analyzing challenges to the advancement of pharmacy. Res Social Adm Pharm. 2017;13(2):321-331. https://doi.org/10.1016/j.sapharm.2016.03.001.

15. Hawthorne N, Anderson C. The global pharmacy workforce: a systematic review of the literature. Hum Resour Health. 2009;7(1):48. https://doi.org/10.1186/ 1478-4491-7-48.

16. International Pharmaceutical Federation. Transforming pharmacy and pharmaceutical sciences education in the context of workforce development. 2017. Accessed 14 June 2020. https://www.fip.org/file/138.

17. Mukhalalati B, Bader L, Alhaqan A, Bates I. Transforming the pharmaceutical workforce in the Eastern Mediterranean Region: a call for action. East Mediterr Health J. 2019. Published online 26 February 2019. https://doi.org/10.26719/emhj.19.064.

18. Awad A, Al-Haqan A, Moreau P. Motivations, career aspiration, and learning experience of students in the pharmacy program at Kuwait University: a tool to guide curriculum development. Curr PharmTeach Learn. 2017;9(2):332-338. https://doi.org/10.1016/j.cptl.2016.11.018.

19. Abduelkarem A, Hamrouni AM. The choice of pharmacy profession as a career: UAE experience. Asian J Pharm Clin Res. 2016;9(4):220-226.

20. Saleh GB, Rezk NL, Laika L, Ali A, El-Metwally A. Pharmacist, the pharmaceutical industry and pharmacy education in Saudi Arabia: a questionnaire-based study. Saudi Pharm J. 2015;23(5):573-580. https://doi.org/10.1016/j.jsps.2015.02.019.

21. Alhaddad MS. Undergraduate pharmacy students' motivations, satisfaction levels, and future career plans. J Taibah Univ Med Sci. 2018;13(3):247-253. https:// doi.org/10.1016/j.jtumed.2018.03.004.

22. El-Hammadi M. Career preferences of Syrian students and their attitudes toward a number of practice areas: will community pharmacy continue to dominate the profession? Curr Pharm Teach Learn. 2013;5(5):373-380. https://doi.org/10.1016/j.cptl.2013.03.004.

23. Keshishian F. Factors influencing pharmacy students' choice of major and its relationship to anticipatory socialization. Am J Pharm Educ. 2010;74(4):75. https:// doi.org/10.5688/aj740475.

24. James PB, Batema MNP, Bah AJ, et al. Was pharmacy their preferred choice? Assessing pharmacy students' motivation to study pharmacy, attitudes and future career intentions in Sierra Leone. Health Professions Education. 2018;4(2):139-148. https://doi.org/10.1016/j.hpe.2017.06.001.

25. Willis S, Hassell K, Noyce P. Career intentions of pharmacy students. J Health Serv Res Policy. 2008;13(Suppl 2):45-51. https://doi.org/10.1258/jhsrp.2007. 007112.

26. General Secretariat for Development Planing. Qatar National Vision 2030. July 2008. Accessed 17 May 2020. https://www.psa.gov.qa/en/qnv1/Documents/ QNV2030_English_v2.pdf.

27. PhD in Pharmaceutical Sciences. Qatar University College of Pharmacy. January 2019. Accessed 17 May 2020. http://www.qu.edu.qa/pharmacy/departments/ programs/phd-in-pharmaceutical-sciences.

28. Said Z, Summers R, Abd-El-Khalick F, Wang S. Attitudes toward science among grades 3 through 12 Arab students in Qatar: findings from a cross-sectional national study. Int J Sci Educ. 2016;38(4):621-643. https://doi.org/10.1080/09500693.2016.1156184.

29. J.W. Creswell C.N. Poth Qualitative Inquiry and Research Design: Choosing among Five Approaches 4th ed. 2013 SAGE Publications Inc.

30. Mukhalalati B, Awaisu A. Principles, paradigms, and application of qualitative research in pharmacy practice. In: Babar ZD, ed. Encyclopedia of Pharmacy Practice and Clinical Pharmacy. Elsevier; 2019: 162-172. https://doi.org/10.1016/B978-0-12-812735-3.00622-1.

31. R.K. Yin Case Study Research: Design and Methods 5th ed. 2014 SAGE Publications Inc.

32. Awaisu A, Mukhalalati B, Ibrahim MIM. Research designs and methodologies related to pharmacy practice. In: Babar ZD, eds. Encyclopedia of Pharmacy Practice and Clinical Pharmacy. Elsevier; 2019: 7-21. https://doi.org/10.1016/B978-0-12-812735-3.00602-6.

33. Halcomb EJ, Davidson PM. Is verbatim transcription of interview data always necessary? Appl Nurs Res. 2006;19(1):38-42. https://doi.org/10.1016/j.apnr.2005. 06.001 .

34. M.B. Miles A.M. Huberman J. Saldana Qualitative Data Analysis: A Method Sourcebook 3rd ed. 2014 SAGE Publications Inc.

35. Y.S. Lincoln E.G. Guba Naturalistic Inquiry 1985 SAGE Publications Inc.

36. Braun V, Clarke V. Using thematic analysis in psychology. Qual Res Psychol. 2006;3(2):77-101. https://doi.org/10.1191/1478088706qp063oa.

37. J. Saldaña The Coding Manual for Qualitative Researchers 3rd ed. 2015 SAGE Publicaions.

38. Clark S. Canadian Baccalaureate nurses transition to the local health care environment in Qatar. 29 January 2016. Accessed 17 May 2020 . https://prism.ucalgary. ca/bitstream/handle/11023/2791/ucalgary_2016_clark_sheila.pdf? sequence = \&isAllowed =y.

39. Shen G, Fois R, Nissen L, Saini B. Course experiences, satisfaction and career intent of final year preregistration Australian pharmacy students. Pharm Pract (Granada). 2014;12(2):392. https://doi.org/10.4321/s1886-36552014000200004.

40. Hassan J, Hassan A, King ML. Nursing image in Qatar: past, present and future. Middle East J Nurs. 2012;6(4):26-28.

41. Critchley K, Saudelli MG. Helping Qatar achieve its National Vision 2030: one successful international branch campus. $J$ Edu Thought. 2015;48(12):9-24.

42. N. Kheir Pharmacy practice in Qatar A.I. Fathelrahman M.I. Ibrahim A.I. Wetheimer Pharmacy Practice in Developing Countries 2016 Elsevier 233252.

43. Okasha MS, Ziady HH. Joining the nursing profession in Qatar: Motives and perceptions. East Mediterr Health J. 2001;7(6):1025-1033.

44. Almeer Struggling to Succeed: A Grounded Theory Study of becoming a Nurse in Qatar within Socio-cultural, Educational, and Professional Contexts. Doctor of. Philosophy Thesis. University of Miami; 1998.

45. Capstick S, Green JA, Beresford R. Choosing a course of study and career in pharmacy—student attitudes and intentions across three years at a New Zealand school of pharmacy. Pharm Edu. 2007;7(4):359-373. https://doi.org/10.1080/15602210701673811.

46. Silverthorne J, Price G, Hanning L, Scanlan J, Cantrill J. Factors that influence the career choices of pharmacy undergraduates. Pharm Edu. 2003;3(3):161-167. https://doi.org/10.1080/15602210310001623124. 